\title{
Target Site Delivery and Residence of Nanomedicines: Application of Quantitative Systems Pharmacology
}

\author{
Jessie L.-S. Au, Roberto A. Abbiati, M. Guillaume Wientjes, and Ze Lu \\ Institute of Quantitative Systems Pharmacology, Carlsbad, California (J.L.-S.A., R.A.A., M.G.W., Z.L.); Department of \\ Pharmaceutical Sciences, University of Oklahoma, Oklahoma City, Oklahoma (J.L.-S.A., R.A.A.); Optimum Therapeutics LLC, \\ Carlsbad, California (J.L.-S.A., M.G.W., Z.L.); and College of Pharmacy, Taipei Medical University, Taipei, Taiwan, Republic of \\ China (J.L.-S.A.)
}

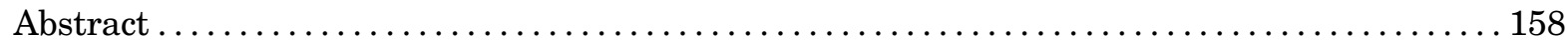

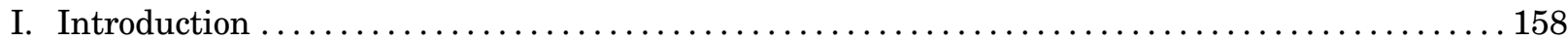

II. Transport from Blood to the Tissue Interstitium ............................ 160

A. Fates of Nanosized Medicine in Blood ............................... 160

B. Differences in Blood and Lymph Vasculatures in Normal and Tumor Tissues Lead to Differences in Nanosized Medicine Extravasation into the Tissue Interstitium......... 160

C. Transport within the Tissue Interstitium .............................. 160

D. Equation for Transvascular and Interstitial Transport $\ldots \ldots \ldots \ldots \ldots \ldots \ldots \ldots \ldots \ldots \ldots$

III. Interactions with the Extracellular Matrix and Cells $\ldots \ldots \ldots \ldots \ldots \ldots \ldots \ldots \ldots \ldots \ldots \ldots 2$

A. Nanosized Medicine Interactions with the Extracellular Matrix and Cells ............ 162

B. Equation for Nanosized Medicine Interactions with Extracellular Matrix and Cells ...... 162

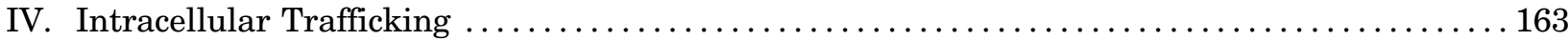

A. Intracellular Processing of Nanosized Medicine ............................ 163

B. Equation for Nanosized Medicine Intracellular Trafficking .................... 163

V. Examples of Applying Quantitative Systems Pharmacology to Estimate the Target Site Delivery and Residence of Small Molecule Drugs and Nanosized Medicines .............. 164

A. Basis for Quantitative Systems Pharmacology-Based Multiscale Modeling and

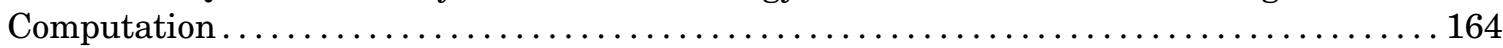

B. Examples of Using Multiscale Modeling and Computation to Determine Target Site Delivery and Residence .................................................. 164

VI. Interaction of Nanosized Medicine and Proteins to Form Protein Corona ................. 165

A. Current Knowledge on Nanosized Medicine-Protein Corona. . . . . . . . . . . . . . . . . . . 165

B. Formation of Nanosized Medicine-Protein Corona ........................... 165

C. Evolution of Nanosized Medicine-Protein Corona with Time In Vitro and In Vivo....... 165

D. Evolution of Nanosized Medicine-Protein Corona with Environment ............... 165

E. Effects of Nanosized Medicine-Protein Corona Formation and Evolution on Target Site Delivery and Residence ....................................... 166

F. Potential Utility of Quantitative Systems Pharmacology in Studying Nanosized Medicine-Protein Corona....................................... 166

Address correspondence to: Jessie L.-S. Au, Institute of Quantitative Systems Pharmacology, 1815 Aston Ave., Suite 107, Carlsbad, CA 92008. E-mail: jau@i-qsp.org

This work was supported in part by the University of Oklahoma [Mosier Chair of Pharmaceutical Sciences], the National Institutes of Health National Cancer Institute [Grants R01-CA158300, R01-CA163015, R43/R44-CA103133, R43/R44-CA107743, and R43-CA162448], the National Institutes of Health National Institute of Biomedical Imaging and Bioengineering [R01-EB015253], the National Institutes of Health National Institute of General Medical Sciences [R01-GM100487], and the National Institutes of Health National Center for Advancing Translational Sciences [R43-TR000356].

A portion of this work was previously presented at the following workshop: Au JLS (2017) Considerations for bioequivalence evaluation of nano-particulate/molecular medicine. U.S. Food and Drug Administration Public Workshop on Leveraging Quantitative Methods and Modeling to Modernize Generic Drug Development and Review; 2017 Oct 2-3; Silver Spring, MD.

https://doi.org/10.1124/pr.118.016816. 
VII. Unique Regulatory Issues Regarding Nanosized Medicine Products . . . . . . . . . . . . 166

VIII. Conclusions and Perspectives .......................................... 167

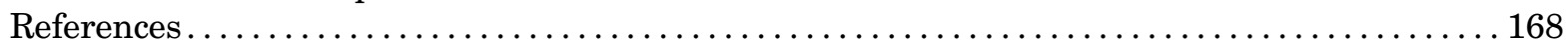

Abstract-Quantitative systems pharmacology (QSP), an emerging field that entails using modeling and computation to interpret, interrogate, and integrate drug effects spanning from the molecule to the whole organism to forecast treatment outcomes, is expected to enhance the efficiency of drug development. Since late 2017, the U.S. Food and Drug Administration has advocated the use of an analogous approach of model-informed drug development. This review focuses on issues pertaining to nanosized medicines (NP) and the potential utility of QSP to determine NP delivery and residence at extracellular or intracellular targets in vivo. The kinetic processes governing NP disposition and transport, interactions with biologic matrix components, binding and internalization in cells, and intracellular trafficking are determined, sometimes jointly, by NP properties (e.g., dimension, materials, surface charge and

\section{Introduction}

Quantitative systems pharmacology (QSP) is an emerging field that is expected to advance pharmaceutical sciences and drug development. QSP entails using modeling and computation to interpret, interrogate, and integrate drug concentrations and effects on multiple scales spanning from the molecule to the whole organism to forecast treatment outcomes. The U.S. National Institutes of Health considers QSP a high priority for research and training program development (https://www.nigms.nih.gov/training/documents/ systemspharmawpsorger2011.pdf). Its importance in the drug development field is highlighted by recent U.S. Food and Drug Administration (FDA) announcements stating that the agency advocates the use of an analogous approach, model-informed drug development, in New Drug Applications and Abbreviated New Drug Applications (https://wayback.archive-it.org/7993/ 20170403224108/https:/www.fda.gov/AdvisoryCommittees/ CommitteesMeetingMaterials/Drugs/AdvisoryCommitteeforPharmaceuticalScienceandClinicalPharmacology/ ucm361585.htm; https://www.fda.gov/AdvisoryCommittees/ CommitteesMeetingMaterials/Drugs/AdvisoryCommitteeforPharmaceuticalScienceandClinicalPharmacology/ ucm535520.htm; https://www.fda.gov/Drugs/NewsEvents/ ucm554182.htm; https://www.fda.gov/drugs/newsevents/ ucm527823.htm) and by the agency's implementation of a model-informed drug development pilot program in April 2018 (U.S. Food and Drug Administration, 2018). modifications, shape, and geometry) and target tissue properties (e.g., perfusion status, vessel pore size and wall thickness, vessel and cell density, composition of extracellular matrix, and void volume fraction). These various determinants, together with the heterogeneous tissue structures and microenvironment factors in solid tumors, lead to environment-, spatial-, and timedependent changes in NP concentrations that are difficult to predict. Adding to the complexity is the recent discovery that NP surface-coating protein corona, whose composition depends on NP properties and which undergoes continuous evolution with time and local protein environments, is yet another unpredictable variable. Examples are provided to demonstrate the potential utility of QSP-based multiscale modeling to capture the physicochemical and biologic processes in equations to enable computational studies of the key kinetic processes in cancer treatments.
This review focuses on the unique issues pertaining to nanosized medicines (NP) and the potential utility of QSP to determine the target site delivery and residence of NP. The emphasis is on solid tumors, which comprise heterogeneous tissue structures and microenvironmental factors that are known to affect drug/NP delivery and residence, drug/NP-biomatrix interactions, and tumor response to treatments. Some aspects of this review were presented at a public FDA workshop in October 2017 (Fang et al., 2018).

In this review, "NP" broadly refers to nanosized entities used in the treatment, diagnosis, monitoring, and control of biologic systems. This includes entities that fall under the FDA definitions of nanotechnology - that is, entities engineered to have a dimension of $\sim 1-100 \mathrm{~nm}$ or entities having a dimension of up to $1000 \mathrm{~nm}$ plus dimension-dependent physical or chemical properties or biologic effects (https://www.fda.gov/downloads/ Drugs/GuidanceComplianceRegulatoryInformation/ Guidances/UCM588857.pdf). There are currently 12 FDAapproved parenteral NP products loaded with active pharmaceutical ingredients, including 7 liposomal preparations, 1 nanoparticle, 1 nanotube, and 3 lipid-drug complexes, with particle sizes between 45 and $150 \mathrm{~nm}$ (Table 1). Additional FDA-approved nanosized entities include 239 proteins and peptides $(>2 \mathrm{kDa}$, typically $>1 \mathrm{~nm})$ (Usmani et al., 2017), 80 antibodies and derivatives $(>40 \mathrm{kDa},>5 \mathrm{~nm}$ ), and 4 antibody-drug conjugates (IgGbased, 149-160 kDa, 15 nm) (https://www.accessdata. fda.gov/scripts/cder/daf/). The FDA has published several

ABBREVIATIONS: BE, bioequivalence; CQA, critical quality attribute; ECM, extracellular matrix; EE, early endosome; FDA, U.S. Food and Drug Administration; FEM, finite element method; LE, late endosome; NP, nanosized medicine; PDE, partial differential equation; PC, protein corona; QSP, quantitative systems pharmacology; RE, recycling endosome; RES, reticuloendothelial system; RLD, reference listed drug; siRNA, small interfering RNA. 
TABLE 1

FDA-approved parenteral NP products containing active pharmaceutical ingredients on the U.S. market as of October 2018

\begin{tabular}{lllccc}
\hline Trade Name & Active Pharmaceutical Ingredient & Formulation & Average Diameter, $\mathrm{nm}$ & Route of Administration & Approval Year \\
\hline Doxil & Doxorubicin & Liposome & 85 & Intravenous & 1995 \\
DaunoXome & Daunorubicin & Liposome & 45 & Intravenous & 1996 \\
AmBisome & Amphotericin B & Liposome & $60-70$ & Intravenous & 1997 \\
Visudyne & Verteporfin & Liposome & $18-104$ & Intravenous & 2000 \\
Marqibo & Vincristine sulfate & Liposome & 100 & Intravenous & 2012 \\
Onivyde & Irinotecan HCL & Liposome & 110 & Intravenous & 2015 \\
Vyxeos & Daunorubicin/cytarabine & Liposome & 100 & Intravenous & 2017 \\
Abraxane & Paclitaxel & Nanoparticle & 130 & Intravenous & 2005 \\
Somatuline & Lanreotide acetate & Nanotube & 24 & Subcutaneous & 2007 \\
Abelcet & Amphotericin B & Lipid complex & $1600-11,100$ & Intravenous & 1995 \\
Amphotec & Amphotericin B & Lipid complex & 150 & Intravenous & 1996 \\
Onpattro & Patisiran & Lipid complex & $<100$ & Intravenous & 2018 \\
\hline
\end{tabular}

Note that Abelcet is included in an FDA NP product list (Bobo et al., 2016; Zheng et al., 2017) but has been reported to have an average diameter of $>1000 \mathrm{~nm}$ (Clark et al., 1991; Johnson et al., 1998).

guidance documents for industry related to nanotechnology products; the latest draft guidance was published on December 2017 (https://www.fda.gov/downloads/Drugs/ GuidanceComplianceRegulatoryInformation/Guidances/ UCM588857.pdf).

The efficacy of NP depends on the delivery and residence at the intended target site. Potential target sites are the tissue interstitium (e.g., diagnostics or therapeutics), cell membrane (e.g., antibodies), or intracellular compartments (e.g., DNA, antisense, RNA interference). Figure 1 shows the multiple processes involved in NP delivery from the injection site to the extracellular or intracellular target. As discussed below, there are many intersecting kinetic processes that ultimately determine the target site delivery of an NP and its cargo, and many of these processes are determined by NP properties as well as by tissue properties. In addition, some of these processes produce opposite outcomes; for example, a surface modification of an NP, such as pegylation, confers stealthiness to reduce clearance by the reticuloendothelial system (RES) but also reduces the cell membrane binding and subsequent endocytosis. The complexity of the system makes it a fertile ground for QSP research in which the physicochemical and biologic processes can be described in mathematical terms and models, so as to enable the use of computation to study how changes in individual NP or tissue properties, singly or in combination, affect the target site exposure.

The remaining sections of this review focus on the processes and determinants of NP exposure at target sites and the QSP-based approaches to depict and compute these dynamic and intersecting processes. Section II discusses the processes governing, and the factors affecting, the transport of NP and cargo from the injection site to the tumor interstitium. Section III discusses the interactions of NP with extracellular matrix (ECM) components and cells. Section IV discusses the NP internalization into cells and the intracellular NP trafficking through endocytic organelles. These three sections jointly describe the numerous determinants and barriers affecting drug/NP transport to the intended extracellular or intracellular target sites in tissues in general and solid tumors in particular. Readers are referred to our earlier reviews for more details and original citations on these aspects (Au et al., 2001,

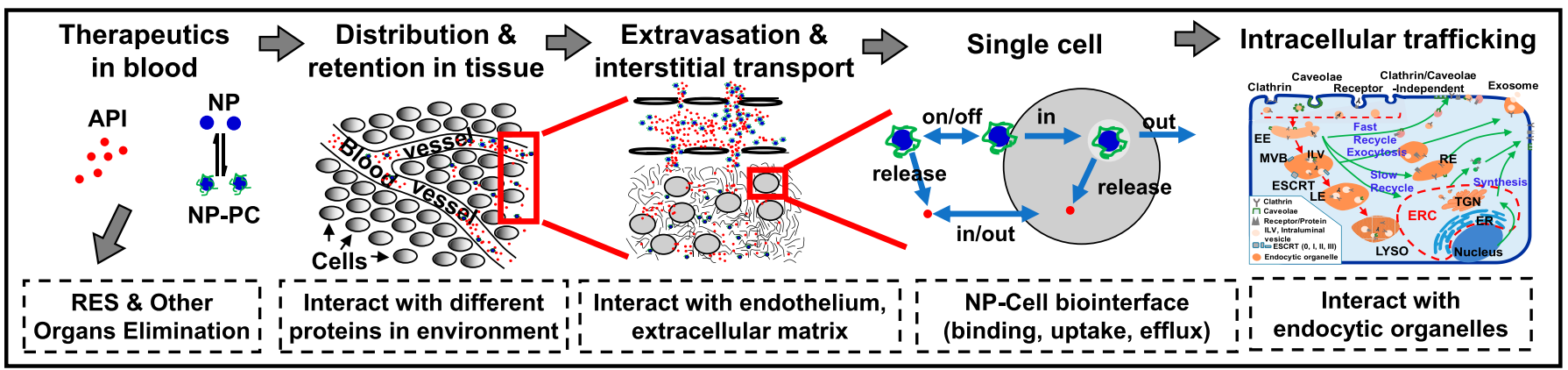

Fig. 1. Transport of NP from the injection site to the target site. After an intravenous injection, NP are distributed in blood and undergo the following processes: 1) interaction with proteins in blood to form NP-PC, 2) removal by phagocytic/RES entrapment or elimination by metabolism and excretion, 3) transport to organs and tissues via blood circulation, 4) extravasation into the tissue interstitium via transvascular diffusion or convection, 5) interaction with ECM components, 6) transport by interstitial diffusion and convection to reach individual cells, 7) interaction with cells (binding, internalization, efflux), and 8) intracellular trafficking and interaction with endocytic organelles. The drawing of NP, ECM components, and subcellular organelles is not to scale. Note that the proteins on the PC formed in blood may exchange with proteins in ECM (not depicted in the figure). See the text for more details on individual processes. API, active pharmaceutical ingredient; ER, endoplasmic reticulum; ERC, endocytic recycling compartment; ESCRT, endosomal sorting complexes required for transport; ILV, intraluminal vesicle; LYSO, lysosome; MVB, multivesicular body; TGN, trans-Golgi network. This figure is adapted from $\mathrm{Li}$ et al. (2012) and reprinted with permission. 
2002, 2015, 2016; Jang et al., 2003; Lu et al., 2010, 2015; Wang et al., 2010, 2011; Li et al., 2012). Sections II, III, and IV also provide the equations describing the individual kinetic processes, whereas section $\mathrm{V}$ provides examples of applying these equations to compute the spatial-, environment- and time-dependent target site exposure of small molecule drugs and NP. Section VI discusses a unique NP property - that is, the formation and evolution of protein corona (PC). As of this writing, relatively little is known about $\mathrm{PC}$ except that it can affect NP transport and interactions with biologic matrices, and therefore is likely to play a role in the efficacy of nanomedicines. Section VII discusses the regulatory issues regarding NP therapeutics. Finally, section VIII summarizes the key information and discusses the potential application of QSP to unravel the understudied kinetic processes in cancer treatments.

\section{Transport from Blood to the Tissue Interstitium}

\section{A. Fates of Nanosized Medicine in Blood}

In blood, NP can undergo degradation (e.g., due to carrier instability), interact with blood components (e.g., interact with proteins to form PC, enter blood cells), undergo surface opsonization and subsequent entrapment by the mononuclear phagocytic system and RES, or be excreted by the kidneys (e.g., for small NP with a $<6$-nm diameter) (Nie, 2010). The remaining NP is transported via the blood circulation to the target organs and is extravasated by transvascular diffusion or convection to enter the tissue interstitium. NP cargo such as small molecule drugs can be released from NP within systemic blood or the tissue interstitium or intracellularly; the released cargo can interact with blood components, undergo elimination, or be transported to its intended targets.

\section{B. Differences in Blood and Lymph Vasculatures in Normal and Tumor Tissues Lead to Differences in Nanosized Medicine Extravasation into the Tissue Interstitium}

In humans, blood flow velocity and pressure in blood vessels decreases with vessel diameter (e.g., from $\sim 20 \mathrm{~cm} / \mathrm{s}$ and $\sim 100 \mathrm{mmHg}$, respectively, in large arteries to $\sim 0.03 \mathrm{~cm} / \mathrm{s}$ and $\sim 20 \mathrm{mmHg}$ in small capillaries). Openings in the capillary wall range from small pores on endothelial cells to large openings due to discontinuous cell junctions and vary among organs (e.g., between 5 and $15 \mathrm{~nm}$ in most tissues, $60 \mathrm{~nm}$ in the bone marrow and lungs, $70-90 \mathrm{~nm}$ in the kidneys, $\sim 135 \mathrm{~nm}$ in hepatic sinusoid, and up to $5 \mu \mathrm{m}$ in the terminal arterial capillary network of the splenic red pulp reticulum) (Sarin, 2010). Compared with normal tissues, tumor vasculature is typically disorganized, resulting in chaotic and tortuous paths and greater flow resistance. On the other hand, tumor blood vessels have much larger openings (100-780 nm) and are much leakier. In addition, larger tumors show heterogeneous blood vessel distribution, with a central avascular or necrotic region, an intermediate seminecrotic and poorly perfused region, and a stably perfused periphery. Normal tissues have functional lymphatic systems, whereas tumors typically do not. These differences in blood and lymph vasculatures can either promote or reduce NP delivery to tumors. For example, absence of interstitium-lymphatic fluid drainage in tumors increases the interstitial fluid pressure and thereby limits the transvascular and interstitial convective transport but also enhances the retention of NP. In addition, the larger tumor capillary pore/opening sizes enhance the ease of NP extravasation into the interstitial space. The spatial-dependent differences in blood vessel density and perfusion status within a tumor contribute to the uneven intratumoral drug/NP distribution.

Most of the knowledge regarding vasculatures and drug/NP delivery in tumors was obtained from preclinical models. Recent advances in intravital highresolution imaging in tumors of human patients in the clinical setting reveal that 1) vessels are disorganized and tortuous, as observed in animal tumors; 2 ) $\sim 50 \%$ of tumor vessels are not open; and 3) vessel diameters are larger and vessel wall shear stress is lower than predicted from immunohistochemistry or preclinical intravital microscopy results (Fisher et al., 2016; Gabriel et al., 2018).

\section{Transport within the Tissue Interstitium}

The effects of NP properties, including size, surface charge or modifications, shape and geometry, and nanomaterials, on NP disposition and interactions with $\mathrm{ECM} /$ cells are summarized in Table 2 . With respect to tissue properties, the fibrous proteins (e.g., collagen, elastin, fibronectin) and polysaccharides (e.g., hyaluronan, glycosaminoglycan) in ECM and tumor cells present physical resistance to interstitial diffusional and convective transport. The high interstitial fluid pressure, secondary to the absence of lymphatic drainage and accumulation of macromolecules and wastes, reduces the transvascular and interstitial convective transport. The smaller void volume fraction and, conversely, higher density of tumor cells or ECM components reduces the tissue porosity and NP diffusivity, whereas binding to ECM components or cells reduces the free NP fraction available for convective or diffusive transport (Au et al., 2001, 2002, 2015, 2016; Jang et al., 2003; Lu et al., 2010, 2015; Wang et al., 2010, 2011; $\mathrm{Li}$ et al., 2012; Abbiati and $\mathrm{Au}, 2018$ ).

\section{Equation for Transvascular and Interstitial Transport}

The transvascular and interstitial convective and diffusive transport processes are determined by dimension- and nanomaterial-dependent factors. These include 12 tissue properties [i.e., hydraulic 
TABLE 2

Effect of NP properties

\begin{tabular}{|c|c|}
\hline NP Property & Outcome/Effect (Example) \\
\hline \multirow[t]{4}{*}{ Size } & Reduced opsonization and RES uptake at $<200 \mathrm{~nm}$ \\
\hline & $\begin{array}{l}\text { Affects transport (transvascular and interstitial) and retention (enhanced in tumors for } \\
50-200 \mathrm{~nm} \text { NP) }\end{array}$ \\
\hline & Internalization of inorganic NP and liposomes (maximum at $30-50 \mathrm{~nm}$ ) \\
\hline & Intracellular trafficking/processing \\
\hline \multirow{4}{*}{ Surface charge } & Affects opsonization (rapid RES clearance of cationic liposomes) \\
\hline & Affects electrostatic interaction with vessel pore \\
\hline & Promotes interactions with ECM components, reduces interstitial transport \\
\hline & $\begin{array}{l}\text { Increases binding to cell membrane and internalization (positively charged NP shows higher } \\
\text { binding and internalization compared with neutral or negatively charged NP) }\end{array}$ \\
\hline \multirow[t]{5}{*}{ Biomaterial and surface modification } & Coating with hyaluronic acid reduces immunogenicity \\
\hline & Cationic cell-penetrating peptide promotes NP internalization and perinuclear localization \\
\hline & Collagenase and hyaluronidase alter ECM, promote interstitial transport \\
\hline & $\begin{array}{l}\text { Ligands for targeting (e.g., folate, transferrin, CD19, CD20, uPAR, HER2) enhances uptake and } \\
\text { accumulation }\end{array}$ \\
\hline & pH-sensitive fusogenic polymers, peptides, or lipids enhance cargo release in endosomes \\
\hline \multirow[t]{8}{*}{ Shape and geometry } & Higher curvature leads to a larger degree of membrane wrapping \\
\hline & Higher uptake of spherical NP vs. rod-shaped NP in murine macrophages and human HeLa cells \\
\hline & $\begin{array}{l}\text { Higher uptake of nanorods with shorter aspect ratio (length-to-width) in HeLa and human breast } \\
\text { MCF7 cells vs. longer ratio, whereas the opposite was found for cationic crosslinked pegylated } \\
\text { hydrogel NP in HeLa cells }\end{array}$ \\
\hline & Lower uptake for smaller NP (100 and $300 \mathrm{~nm})$ vs. larger NP with the same aspect ratio \\
\hline & $\begin{array}{l}\text { For mesoporous silica NP, spherical NP uses clathrin-mediated endocytosis, whereas the rod- or } \\
\text { worm-shaped analogs prefer macropinocytosis }\end{array}$ \\
\hline & $\begin{array}{l}\text { Gold nanorods align to cell membrane in a near-parallel manner followed by rotating by } \sim 90^{\circ} \text { to } \\
\text { enter the cell via a caveolae-mediated pathway }\end{array}$ \\
\hline & $\begin{array}{l}\text { Molecular dynamic simulations suggest slow membrane wrapping of NP with sharp edges or high } \\
\text { curvature (e.g., cubes) }\end{array}$ \\
\hline & $\begin{array}{l}\text { Shape of NP affects biodistribution; for example, } 1 \text { ) longer circulation for higher aspect ratio NP } \\
\text { (e.g., filomicelles, rods) vs. spherical NP; } 2 \text { ) discoidal/plate-like NP accumulate in the heart and } \\
\text { lungs, presumably due to the margination under flow leading to the accumulation on vascular } \\
\text { walls; and 3) spheres and short rods tend to accumulate more in the liver than longer rods, } \\
\text { whereas NP with a higher aspect ratio concentrate more in the spleen and lungs }\end{array}$ \\
\hline
\end{tabular}

Readers are referred to earlier reviews (Wang et al., 2010; Li et al., 2012; Andar et al., 2014; Shang et al., 2014; Paliwal et al., 2015; Treuel et al., 2015; Au et al., 2016; Yang

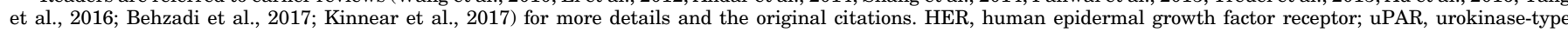
plasminogen activator receptor.

conductivity of microvessel walls $\left(L p_{\mathrm{v}}\right)$, osmotic pressure in blood $\left(\pi_{\mathrm{v}}\right)$ and in interstitial fluid $\left(\pi_{\text {int }}\right)$, protein reflection coefficient across the vascular wall $\left(\sigma_{\mathrm{p}}\right)$, pressure in blood vessels $\left(P_{\mathrm{v}}\right)$ and interstitial fluid $\left(P_{\text {int }}\right)$, interstitial fluid flow velocity $(\vec{u})$, blood vessel surface area per unit of tissue volume $(S / V)$, maximum NP binding sites per unit of tissue volume $\left(B_{\max }\right)$, hydraulic conductivity of lymphatic vessel walls $\left(L p_{1}\right)$, lymphatic vessel surface area per unit of tissue volume $\left(S_{1} / V\right)$, and lymphatic vessel pressure $\left.\left(P_{1}\right)\right]$ and multiple factors that are jointly determined by both NP and tissue properties. For example, NP size relative to vessel pore size and vessel wall thickness determine the reflection coefficient $\sigma$ and vascular diffusive permeability $\left(P_{\mathrm{d}}\right)$, and NP size relative to tissue void volume fraction as well as NP interactions with host organs and ECM or cells determine its interstitial diffusion coefficient $(D)$. These physicochemical processes are captured in several well established equations, such as convective transport described by the combination of the Starling equation, Darcy's law, and mass and momentum conservation laws and diffusive transport described by Fick's First and Second laws (eqs. 1 and 2); the individual transport processes are denoted underneath the corresponding mathematic terms. Please see our earlier publications for the mathematic basis of these equations (Au et al., 2014).

\section{Extravasation from blood vessel (Eq. 1)}

$$
\begin{aligned}
& \boldsymbol{\theta}=\boldsymbol{L} \boldsymbol{p}_{v} \cdot(\mathbf{1}-\boldsymbol{\sigma}) \cdot\left(\boldsymbol{P}_{v}-\boldsymbol{P}_{\text {int }}-\sigma_{\boldsymbol{p}} \cdot\left(\boldsymbol{\pi}_{v}-\boldsymbol{\pi}_{\text {int }}\right)\right) \cdot \frac{S}{V} \cdot C_{b l o o d}+\boldsymbol{P}_{d} \cdot \frac{S}{V} \cdot\left(C_{b l o o d}-C_{\text {int }}\right) \frac{P e_{v}}{\exp \left(P e_{v}\right)-1} \\
& \text { Extravasation Convective transport (pressure gradient) } \\
& \text { Diffusive transport (concentration gradient) }
\end{aligned}
$$

\section{Interstitial transport (Eq. 2)}

$$
\begin{gathered}
\frac{\partial C_{i n t}}{\partial t} \\
\text { Extravasation Diffusion Convection } \\
=\theta+D
\end{gathered}
$$


Note that the partial differential equation (PDE), such as eq. 2, captures the spatiotemporal-dependent processes. Hence, spatial-dependent properties (e.g., differences in normal and tumor tissues) as well as the intratumoral heterogeneities (e.g., high vessel density in the tumor periphery and low density in the tumor center) can be accounted for by using model parameter values specific to individual spatial locations within the system. The PDE is solved using the computational finite element method (FEM), a numerical method for solving PDE-based engineering problems. In the FEM, the geometry of the system under study is virtually recreated using a computeraided design tool, divided into smaller subdomain or finite elements, each represented by a set of simpler, spatial-independent element equations in place of the original PDE (Flynn et al., 1974; Macheras and Iliadis, 2006; Keener and Sneyd, 2009; Sharma, 2010; Müller and Kuttler, 2015). An example of using the FEM to solve the mass transport PDE, to depict the time- and spatial-dependent distribution of a smaller molecule drug in a solid tumor, is detailed elsewhere (Au et al., 2014).

The above transport models are applicable to an NP that is not bound to macromolecules. For NP that bind to tumor cells or ECM components, the concentration of the free or unbound NP available for diffusive transport needs to be adjusted (e.g., see eq. 3 in section III).

\section{Interactions with the Extracellular Matrix and Cells}

\section{A. Nanosized Medicine Interactions with the Extracellular Matrix and Cells}

NP may bind to cell membrane via specific binding (e.g., ligand-receptor interaction) or nonspecific binding driven by electrostatic interactions. The membrane binding facilitates the subsequent internalization. In general, positively charged NP bind more readily to the cell membrane compared with neutral or negatively charged NP (Table 2). After binding, NP enter cells via multiple mechanisms; the internalization involves an elaborated sequence of coordinated events (Khalil et al., 2006; Mathivanan et al., 2010; Huotari and Helenius, 2011). Among the micropinocytosis mechanisms that take up macromolecules or other chemical substances into cells by membrane invagination, caveolae-mediated endocytosis is used by smaller NP $(\sim 50-100 \mathrm{~nm}$ diameter) and clathrin-mediated endocytosis by larger NP ( 100-150 nm) (Rejman et al., 2004; McMahon and Boucrot, 2011). Nucleation of clathrin domains, which cover about $0.5 \%-2 \%$ of the cell surface, promotes the assembly of clathrin triskelions, induces invagination of the membrane into clathrin-coated pits, and stabilizes the membrane curvature, resulting in clathrin-containing vesicles. The vesicle is detached from the membrane and released into the cytoplasm through the recruitment and action of dynamin, a membrane scission protein, at the neck of the budding vesicle. This is followed by disassembly of the clathrin coat and the clathrin triskelions are recycled back to the membrane. Caveolae are flaskshaped membrane invaginations that are $50-80 \mathrm{~nm}$ in size and lined with caveolin, a dimeric protein that binds cholesterol onto the cellular surface for intracellular trafficking. Caveolae-mediated endocytosis also uses dynamin as the scission protein. NP that use clathrinmediated endocytosis for internalization frequently end up in the lysosomes, whereas NP that use caveolindependent endocytosis can sometimes escape lysosomal degradation. Clathrin- and caveolae-independent endocytoses are not well understood, but they take place in cells devoid of both clathrin and caveolae and are generally related to cholesterol-rich rafts with a diameter of $40-50 \mathrm{~nm}$ in the cell membrane; these small rafts can presumably be captured by and internalized within any endocytic vesicle (Doherty and McMahon, 2009; Behzadi et al., 2017; Kinnear et al., 2017). There are several other nonreceptor-mediated internalization mechanisms, including 1) fluid phase macropinocytosis, in which cytoskeleton rearrangement leads to cell membrane extensions that then fuse back onto the membrane to form a large vesicle $(0.2-5 \mu \mathrm{m}) ; 2)$ passive penetration of quantum dots $(4 \mathrm{~nm})$ into red blood cells as a result of increased membrane flexibility; and 3) disruption of membrane-mimicking lipid bilayers by organic and inorganic NP to cause formation of nanopores to enable NP penetration (Mercer and Helenius, 2009; Oh and Park, 2014; Behzadi et al., 2017). NP such as liposomes can also enter cells via fusion of the NP lipid-bilayer with the cell membrane, followed by release of NP cargo directly into cytosol (Lu et al., 2009; Schroeder et al., 2010). A recent example shows that the fusion of a nanoparticlestabilized nanocapsule/small interfering RNA (siRNA) complex $(\sim 180 \mathrm{~nm})$ with the cell membrane in a cholesterol-dependent process represents an efficient approach for direct cytoplasmic delivery of siRNA (Jiang et al., 2015).

The binding and internalization of NP into cells depends on the NP concentrations and, in the event of receptor-mediated internalization, also the receptor availability and therefore follows first-order or saturable kinetics. The internalized NP may undergo exocytosis to re-enter the extracellular or interstitial fluid (Oh and Park, 2014; Behzadi et al., 2017).

\section{B. Equation for Nanosized Medicine Interactions with Extracellular Matrix and Cells}

Equation 3 shows the ordinary differential equations depicting concentration- and time-dependent extracellular binding, internalization, and exocytosis via a receptor-mediated mechanism.

$N P_{\text {bound }}, N P_{\mathrm{EC}}$, and $N P_{\mathrm{IC}}$ are the respective concentration of membrane-bound, extracellular, and 
NP binding to cell membrane and internalization (Eq. 3)

$$
\begin{aligned}
& \frac{d N P_{\text {bound }}}{d t}=k_{o n, N P} \cdot N P_{E C} \cdot\left(B_{\max , N P}-N P_{\text {bound }}\right)-k_{o f f, N P} \cdot N P_{b o u n d}-k_{i n, N P} \cdot N P_{b o u n d} \\
& \frac{d N P_{I C}}{d t}=k_{i n, N P} \cdot N P_{b o u n d}-k_{\text {exocytosis }} \cdot N P_{I C}-k_{i} \cdot N P_{I C}
\end{aligned}
$$

intracellular NP. These various NP concentrations can be experimentally measured and used to obtain the respective rate constant of NP binding to the cell membrane $\left(k_{\mathrm{on}, \mathrm{NP}}\right), \mathrm{NP}$ dissociation from cell membrane binding sites $\left(k_{\text {off,NP}}\right), \mathrm{NP}$ internalization $\left(k_{\mathrm{in}, \mathrm{NP}}\right), \mathrm{NP}$ exocytosis $\left(k_{\text {exocytosis }}\right)$, and the maximum number of NP binding sites on the cell membrane $\left(B_{\max }\right) . k_{\mathrm{i}}$ is the firstorder rate constant for an intracellular process such as degradation (e.g., in lysosomes; see section IV). Examples of the calculations are shown in our earlier publications (Gao et al., 2013; Wientjes et al., 2014; Wang et al., 2017).

For nonreceptor-mediated internalization, with the exception of passive diffusion that would follow a firstorder concentration gradient-driven process, the other processes involve cytoskeleton or membrane changes that, to our knowledge, have not yet been described in mathematical terms.

\section{Intracellular Trafficking}

\section{A. Intracellular Processing of Nanosized Medicine}

The far-right panel of Fig. 1 shows the schematic illustration of the known NP intracellular trafficking processes. The vesicles are internalized and become a part of early endosomes (EE). The two proposed models regarding EE organization are 1) fusion of vesicles (e.g., clathrin- or caveolin-containing vesicles) with each other to form the larger EE (Helenius et al., 1983) and 2) delivery of the vesicles to the preexisting EE (Oh and Park, 2014; Behzadi et al., 2017; Naslavsky and Caplan, 2018). Although it remains unclear which model is prevalent, the general consensus is that contents in EE are sorted into fast or slow recycling endosomes (REs), which return the contents (e.g., membrane receptor) to
(LEs; pH 5 to 6) and then to the enzyme-rich lysosomes ( $\mathrm{pH} 4.5-5)$ or migrate to a pericellular location where their contents are released as exosomes. Exosomes are small membrane vesicles with an average diameter of between 30 and $100 \mathrm{~nm}$ (Raposo and Stoorvogel, 2013), and they can have diverse biologic functions (van Niel et al., 2018). For example, exosomes derived from cancer cells are involved in distal metastatic niche initiation (Melo et al., 2014; Costa-Silva et al., 2015), intercellular communications (e.g., during drug resistance development; Qu et al., 2016; Stone, 2016), and immune system modulation (Robbins and Morelli, 2014; Muller et al., 2016). We recently demonstrated that the exosome is an intercellular drug transfer mechanism with pharmacological consequences (Wang et al., 2017).

\section{B. Equation for Nanosized Medicine Intracellular Trafficking}

Figure 2 shows a kinetic model of intracellular trafficking, in which the transfer of the endocytosed NP among the intracellular organelles is described as a first-order catenary reaction based on the law of mass action. Equation 4 shows the general ordinary differential equation to depict the time-dependent changes in NP concentrations in an endocytic organelle (i.e., firstorder input from an upstream compartment $j$ into a destination compartment $i$ and first-order output to its next downstream compartment $z$ ).

The rate constants for transfer between endocytic compartments (e.g., EE to LE to RE) can be measured by following the appearance and disappearance of the NP (usually labeled with a fluorescent probe) in these organelles (detected by their respective markers; e.g.,

\section{ODE of NP concentration changes with time in endocytic organelles (Eq. 4)}

$$
\frac{d C_{i}}{d t}=\sum_{j}^{N C_{i n}} k_{j-t o-i} \cdot C_{j}-\sum_{z}^{N C_{o u t}} k_{i-t o-z} \cdot C_{i}
$$

the cell membrane. EE can evolve into multivesicular bodies that proceed to either the acidified late endosomes

$$
\begin{aligned}
& \text { with initial conditions } C_{i}(t=0)=C_{0} \\
& \text { NC = number of compartments }
\end{aligned}
$$

Rab5 for EE, Rab7 for LE, and Rab4/Rab11 for RE), where the colocalization of the NP and markers is 


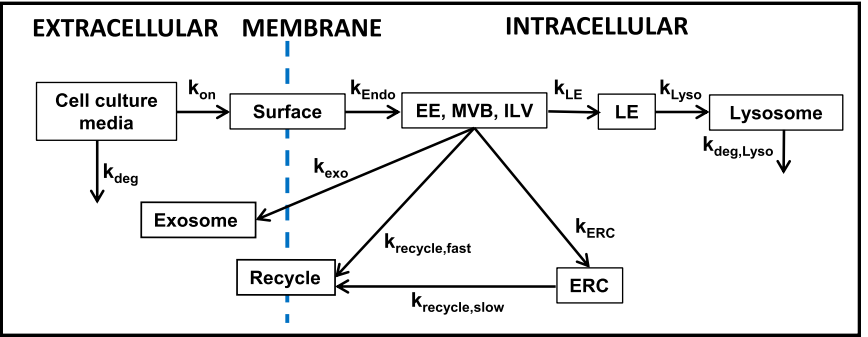

Fig. 2. A kinetic model of intracellular trafficking. This kinetic model is based on the intracellular trafficking scheme shown in the far-right panel of Fig. 1. $k_{\mathrm{x}}$ denotes the inter-compartmental transfer rate constant, with $x$ being the destination compartment. ERC, endocytic recycling compartment; ILV, intraluminal vesicle; MVB, multivesicular body. This figure is adapted from Abbiati and $\mathrm{Au}$ (2018) and reprinted with permission.

monitored using laser confocal microscopy and quantitative imaging software such as Colocalizer Pro and ImageJ. An example of the intracellular trafficking and processing of an siRNA-loaded lipoplex is described elsewhere (Abbiati et al., 2017b).

\section{Examples of Applying Quantitative Systems Pharmacology to Estimate the Target Site Delivery and Residence of Small Molecule Drugs and Nanosized Medicines}

\section{A. Basis for Quantitative Systems Pharmacology- Based Multiscale Modeling and Computation}

As discussed in sections II, III, and IV, the delivery and residence of NP to extracellular or intracellular targets involves multiple kinetic processes that are, in turn, controlled by numerous NP properties and tissue properties. In view of the system complexity, we advocate using QSP-based multiscale models to capture these various scale-, environment-, spatial-, time-, and concentration-dependent processes in order to compute how various NP properties and their changes affect the target site exposure. In these models, a tumor is viewed as a unit in which the intratumoral heterogeneities are represented in mathematical terms (e.g., high blood flow for a highly perfused tumor vs. low blood flow to the necrotic region, or large volume for a primary tumor vs. small volume for a micrometastasis). The numerical values of the respective model parameters are altered and simulations are performed to predict the magnitude of the effects of these diversities on spatiotemporal changes in the target site exposure of small molecule drugs and NP.

\section{B. Examples of Using Multiscale Modeling and Computation to Determine Target Site Delivery and Residence}

Three examples, including two from our group, that used multiscale modeling and the FEM to capture the diverse kinetic processes to calculate drug/NP exposure in tumors are discussed below.
The first example used modeling together with experimental data to evaluate whether liposomes can improve the delivery of doxorubicin to mouse and human tumors in vivo. The simulated results demonstrate that, due to differences in transvascular flux and drug/ liposome deposition among mouse and human tumors, the typical tumor properties in mice would show greater drug levels for the liposomal formulation compared with the free drug, whereas human tumors would not show such benefit under multiple conditions (Hendriks et al., 2012).

The second example demonstrates the use of multiscale modeling to predict the spatiotemporal changes in concentrations of a small molecule drug within a tumor in vivo as functions of other readily measured parameters (in vitro drug-biomatrix interactions, in vivo drug disposition in the peritoneal fluid and whole organism). The whole organism model accounts for drug distribution to various organs and drug clearance from the body, whereas the tumor model accounts for intratumoral heterogeneities, spatial-dependent transport, and drug-biomatrix interactions. These models jointly enabled the prediction of drug concentrations as functions of time and spatial positions within a tumor. The model predictions show good agreement with the experimental results (e.g., $1 \%$ deviation for the area under the curve and $23 \%$ deviations for individual data points); these deviations are severalfold lower compared with the experimental variations between animals (Au et al., 2014).

The third example demonstrates the successful prediction of interstitial diffusive NP transport in a three-dimensional tumor cell spheroid system by a model that accounts for concentration gradientdependent diffusive flux, depletion of the NP due to cell binding and internalization, and the effect of NP-PC. The model was used together with 1) in vitro NP-cell interaction parameters measured in avascular two-dimensional monolayer cell cultures plus 2) interstitial NP diffusivity calculated based on NP and tumor properties (NP size, tumor cell density, interstitial void volume fraction, or concentrations and diameters of ECM components) (Gao et al., 2013; Wientjes et al., 2014).

Other examples of modeling and computation based on PDE and FEM include investigations of tumor properties and pharmacokinetics, such as effects of vasculature normalization on tumor properties (Jain et al., 2007), interstitial fluid flow (Soltani and Chen, 2011), and effects of tumor shape and size on drug residence in tumors (Sefidgar et al., 2014).

Note that QSP model-based simulations in the above examples, as in other model-based simulations, employed a set of model parameter values and yielded single data points (i.e., no data variances), and hence are not suitable for typical statistical analyses that require such variance measurements. 


\section{Interaction of Nanosized Medicine and Proteins to Form Protein Corona}

\section{A. Current Knowledge on Nanosized Medicine-Protein Corona}

A unique feature of NP is the adsorption of proteins on its surface to form PC. This occurs among a wide variety of NP (e.g., metallic, metal oxide, carbon based, polymer coated, polymeric, quantum dots, liposomes) and many proteins in biologic milieu (e.g., apolipoprotein, complement protein, prothrombin, vitronectin, immunoglobulin, fibrinogen, serum albumin). PC was first reported in the mid-2000s and has since been proposed as an important determinant of NP disposition and functionality. Readers are referred to several reviews for more details and original citations (Lai et al., 2012; Monopoli et al., 2012; Treuel and Nienhaus, 2012; Walkey and Chan, 2012; Yang et al., 2013; Setyawati et al., 2015; Au et al., 2016; Barbero et al., 2017; Corbo et al., 2017; Ahsan et al., 2018).

Although protein-lipid interactions have been a major research field for several decades, the knowledge regarding NP-PC is relatively limited. For example, only 226 publications in 2017 contained both "nanoparticle" and "corona" as keywords. Most published studies have focused on analysis of PC protein composition and on NP interactions with single proteins (Huang et al., 2013; Winzen et al., 2015; Zhang et al., 2017; Raoufi et al., 2018). The latter results most likely are oversimplifications, since PC comprises multiple proteins and it is known that binding of one protein to an NP often induces conformational changes that affect the binding of other proteins (Selva Sharma and Ilanchelian, 2015; Vilanova et al., 2016; Raoufi et al., 2018). Two recent reviews suggest using molecular dynamic simulations to address the complexity of PC formation, in the hope of uncovering the major determinants under a wide variety of conditions and thereby improving the clinical translational of nanotechnologies (Ke et al., 2017; Mahmoudi, 2018).

\section{B. Formation of Nanosized Medicine-Protein Corona}

NP-PC formation depends on NP properties (material, surface properties, size, charge, shape, geometry, curvature), environment (ECM composition, $\mathrm{pH}$, temperature, shear stress, ionic strength), and time (Strojan et al., 2017). High shear flow, by inducing conformational changes of proteins in plasminogen-rich $\mathrm{PC}$, reduces NP binding to plasminogen receptors on cells compared with static shear flow (Jayaram et al., 2018). Surface modifications such as pegylation generally decrease PC formation, enabling the NP to avoid recognition and entrapment in the RES (Nuytten et al., 2010; Dobrovolskaia et al., 2014; Bargheer et al., 2015; Pelaz et al., 2015). Decreased NP size leads to higher surface curvature and reduced steric interactions among the pegylation molecules, thereby allowing more proteins to adsorb to the surface (Walkey et al., 2012). Lowering the NP surface positive charge reduces the electrostatic interaction with the negatively charged ECM components and thereby reduces PC formation (Mastorakos et al., 2015).

Figure 3A shows the multilayer PC. The first layer of high-affinity proteins on the NP surface (referred to as hard corona) is covered by a layer of low-affinity proteins (soft corona) (Rahman et al., 2013). Among the several thousand available proteins in human plasma, only a small fraction is present in the hard corona. Equally intriguing is that the proteins in the hard corona are not necessarily the most abundant proteins in plasma or those with the highest affinity for NP (Monopoli et al., 2012). PC formation, mediated by van der Waals forces and electrostatic interactions, occurs rapidly and is completed within minutes (Tenzer et al., 2013).

\section{Evolution of Nanosized Medicine-Protein Corona with Time In Vitro and In Vivo}

PC evolves with time. Figure 3B shows an example of the evolution of $\mathrm{PC}$ in vitro, where the $\mathrm{PC}$ of a silica NP incubated with three proteins with increasing binding affinity (human serum albumin $<$ transferrin $<$ fibrinogen) changed from mostly albumin to mostly fibrinogen, indicating replacement of the low-affinity protein by the high-affinity protein over time (Vilanova et al., 2016).

Figure 3C shows two examples of the time-dependent evolution of PC in vivo, where NP was injected intravenously into CD1 mice (Hadjidemetriou et al., 2015, 2016). The left panel of Fig. 3C shows that both the number and the identity of PC proteins change with time, even though there is no change in the total protein amount (i.e., the number changed from 334 at $10 \mathrm{~min}$ utes to 228 at 1 hour and 284 at 3 hours, with only $~ 50 \%$ of proteins present at all three times). The right panel of Fig. 3C similarly shows substantial changes in the PC proteins of liposomes with different surface modifications (bare or nonpegylated, pegylated, conjugated with cell surface associated mucin 1 transmembrane glycoprotein antibody) at 10 minutes.

\section{Evolution of Nanosized Medicine-Protein Corona with Environment}

The formation and stability of $\mathrm{PC}$, due to the reversibility of noncovalent binding of proteins to the NP surface, depends on the concentrations and types of proteins available in the biologic milieu. Hence, the protein composition of PC evolves as NP translocates from one biologic compartment to another (e.g., from blood to tumor tissues or lymph) (Monteiro-Riviere et al., 2013; Riviere, 2013; Bonvin et al., 2017). 


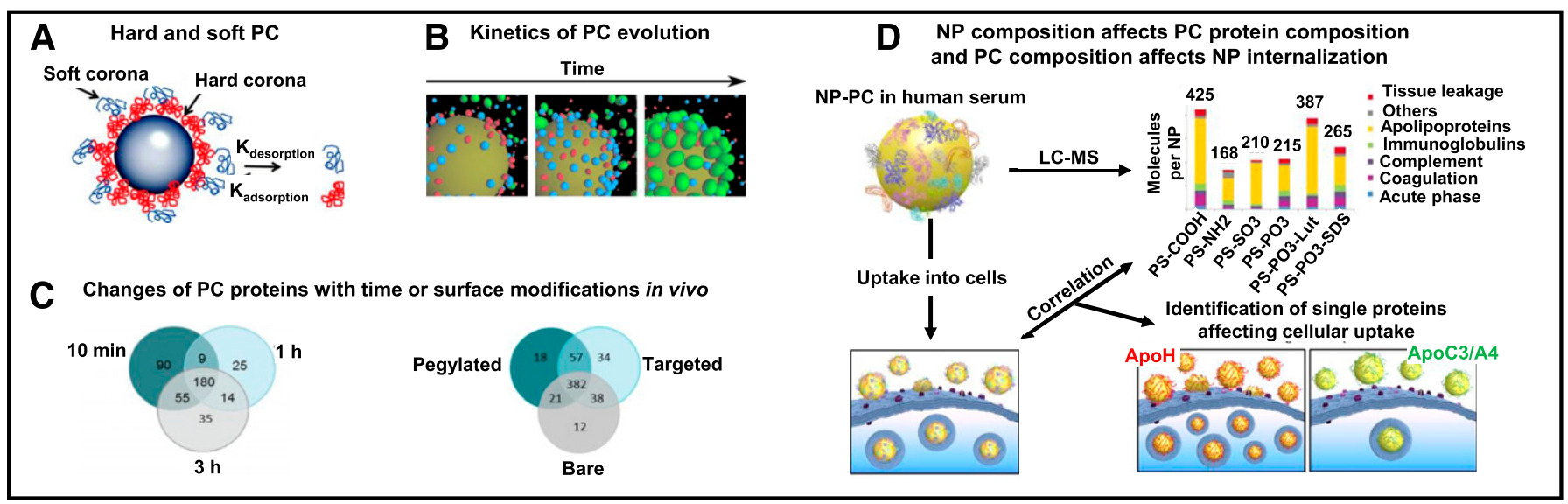

Fig. 3. NP-PC. (A) Schematic illustration of hard and soft PC. The rate of protein adsorption and desorption determines their exchange time and lifetime in PC. The hard or soft PC is composed of multiple proteins. (B) Kinetics of evolution of proteins on PC. Colors indicate the following: red, albumin; blue, transferrin; and green, fibrinogen. (C) Venn diagrams of the numbers of unique proteins adsorbed onto pegylated liposomes recovered from blood of the CD1 mouse at 10 minutes, 1 hour, and 3 hours postinjection (left), and proteins adsorbed onto liposomes with different surface modifications (bare or nonpegylated, pegylated, conjugated with cell surface associated mucin 1 transmembrane glycoprotein antibody) recovered at 10 minutes postinjection (right). (D) NP composition affects PC protein compositions and PC composition affects NP uptake into cells. Analysis of NP-PC with LC-MS shows different PC protein compositions for different PS-COOH NP. Coating of NP by ApoA4 or ApoC3 reduces cellular uptake, whereas coating by ApoH increases uptake. Apo, apolipoprotein; LC, liquid chromatography; MS, mass spectrometry; MUC-1, cell surface associated mucin 1; PS-COOH, carboxy-functionalized polystyrene. Images in this figure were adapted from the following sources and are reprinted with permission: Rahman et al. (2013) (legend also) (A), Vilanova et al. (2016) (B), Hadjidemetriou et al. (2015, 2016) (C), and Ritz et al. (2015) (D).

\section{E. Effects of Nanosized Medicine-Protein Corona Formation and Evolution on Target Site Delivery and Residence}

For NP comprising a nucleic acid-lipoplex or polyplex, interactions with proteins cause destabilization and release of nucleic acid (e.g., DNA and siRNA) (Buyens et al., 2008; Abbiati et al., 2017a). For NP other than a lipoplex or polyplex, the formation of PC has different effects, including an increased effective size (up to $150 \%$ for polystyrene and silica NP), a change of surface charge from positive to neutral or negative, increased opsonization, increased RES uptake, and pathobiological changes such as hemolysis and endothelial cell death (Tenzer et al., 2013; Au et al., 2016). PC on albumin-bound paclitaxel NP acts as a shield and reduces the drug release (Behzadi et al., 2014). In addition, the presence of $\mathrm{PC}$ proteins that are ligands to membrane receptors enhances the NP internalization (Fig. 3D) (Ritz et al., 2015). These changes in turn affect the NP transvascular and interstitial transport, internalization and intracellular processing, and consequently the target site exposure to NP. Similarly, evolution of PC protein compositions can be expected to cause spatial-, environment-, NP/protein concentration-, and time-dependent changes in NP disposition and functionality.

Interspecies differences in PC compositions have been shown to affect NP interactions with macrophages (Müller et al., 2018). Some proteins including complement C3 protein in the PC preformed in human plasma are diminished upon intravenous injection into mice, due to exchange of PC proteins in vivo (Chen et al., 2017).

Serum proteins in humans vary with age, ethnicity, and physiologic or disease state (Hanash, 2003; Conrads et al., 2004). Differences in PC among patients with and without cancer have been reported (Caputo et al., 2017).

In short, the formation and evolution of $\mathrm{PC}$ affects many aspects of NP disposition, transport, and interactions with host tissues or cells and therefore is likely to affect the target site exposure to NP.

\section{F. Potential Utility of Quantitative Systems Pharmacology in Studying Nanosized Medicine-Protein Corona}

In view of the large number of variables affecting NP-PC and their wide-ranging effects on multiple processes that determine the target site exposure, QSP would be a useful tool to interrogate the dynamic systems governing PC formation or evolution and their biologic consequences. However, many of the required qualitative and quantitative background information is currently unavailable, including data on the following: 1) effects of $P C$ on the delivery, transport, residence, and internalization of NP; 2) exchange of PC proteins in different biologic matrices, as functions of time, concentrations of NP, and/or concentrations of proteins of interest; 3) effects of NP composition on PC formation and stability; 4) species differences; and 5) effects of physiologic and disease states. We propose that such background information is needed to improve the in vitro to in vivo and the animal to human translation of nanotechnologies.

\section{Unique Regulatory Issues Regarding Nanosized Medicine Products}

Drug exposure at the target site is a critical determinant of treatment efficacy. FDA approval of generic 
drugs requires the generic product to be pharmaceutically equivalent to the reference listed drug (RLD) and to demonstrate bioequivalence (BE) when administered to patients under the conditions specified in the RLD product labeling. For BE, the FDA requires the confidence interval for the ratio of the averages (population geometric means) of measures for test and reference products to be within a limit, usually $80 \%-125 \%$ (https:// www.fda.gov/downloads/drugs/guidances/ucm070244.pdf; https://www.fda.gov/downloads/Drugs/.../Guidances/ UCM134846.pdf; https://www.fda.gov/downloads/drugs/ guidances/ucm377465.pdf).

Since target site exposure data are usually not available, systemic exposure is often used as the surrogate measurement of $\mathrm{BE}$, with the assumption that systemic $\mathrm{BE}$ equals target site $\mathrm{BE}$. As discussed throughout this article, there are multiple dynamic processes and numerous factors affecting the delivery and residence of an NP and its cargo at the target site. Compounding this problem is the unpredictability due to the PC formation and the continuous exchanges of $\mathrm{PC}$ proteins with the proteins in the local environment. In other words, target site BE of NP products is achieved only when there is equivalence in each and every step involved in the delivery or removal of the NP from the injection site to the target site, including NP disposition and clearance on the whole organism level, transvascular and interstitial transport on the target organ level, internalization on the target cell level, interactions with subcellular organelles, release of cargo on each level (whole organism, organ, cell), interactions with proteins on each level, and interactions with ECM and intracellular endocytic organelles. Given this level of complexity, it is reasonable to expect that systemic $\mathrm{BE}$ of NP does not equal target site $\mathrm{BE}$ and, accordingly, the conventional systemic BE determination used to evaluate small molecular drugs does not apply to NP products.

A recent publication from the FDA outlines the paradigm for $\mathrm{BE}$ recommendation of parenteral $\mathrm{NP}$ products, which calls for formulation sameness and systemic BE (Zheng et al., 2017). However, formulation sameness may be difficult to achieve if the production of generic NP uses a different manufacturing process. On the other hand, regulatory decisions can be facilitated by 1) determining which NP properties will significantly alter the target site exposure and therefore cause systemic $\mathrm{BE}$ to not equal target site $\mathrm{BE}$ [i.e., the critical quality attributes or (CQAs)]; 2) determining, conversely, which NP properties are non-CQAs; 3) determining to what extent differences in CQAs and non-CQAs will (and will not) result in unacceptable changes in target site exposure rendering the generic NP to not have target site $\mathrm{BE}$ to RLD; and 4) determining the effects of PC on NP delivery and residence, including the effects of hostdependent factors (e.g., age, sex, ethnicity, physiologic and disease states) on PC formation and evolution in human subjects. In addition, QSP-based multiscale modeling represents a potentially useful tool in these endeavors, such as in assessing the quantitative relationship between individual NP properties (singly and in combinations) versus systemic and target site exposure to NP and cargo.

\section{Conclusions and Perspectives}

A major challenge in cancer nanotechnology is the inability of translating the successes in animals to humans (Prabhakar et al., 2013; Au et al., 2016). This could be a result of the many intersecting kinetic processes and the numerous variables causing scale-, environment-, and spatio-temporal-dependent changes in the target site exposure of NP. For example, the structural differences between animal and human tumors (e.g., larger size with greater stroma/ECM fraction in human tumors) would affect the NP transport. A better understanding of the interspecies differences in the tumor properties and the resulting differences in physicochemical processes such as transvascular and interstitial transport or NP-biomatrix interaction, together with QSP modeling to account for these differences, may facilitate the scale-up of animal data to forecast the likely outcomes in humans.

Second, although NP such as liposomes and polymeric NP have been studied for $\geq 40$ years, the presence of PC was first recognized about 10 years ago. Because of its "newness," relatively little information is available. We advocate additional research to obtain qualitative and quantitative data on the formation and evolution of PC. Such information can be used with modeling and computation to advance the knowledge on the effects of PC.

Third, the dimension- and material-dependent effects of NP, as they affect the target site pharmacokinetics and pharmacodynamics, present new challenges for regulatory decisions. This is in part because the established FDA guidelines to demonstrate BE for small molecule drugs are based on the assumption of kinetic equilibrium between the systemic circulation and the target site, which is likely not applicable to NP products.

Finally, this review outlines several QSP approaches to account for the time- and spatial-dependent effects of various factors on drug/NP delivery and residence in tumors. Another potential application of QSP models, once they have been established and validated, is to interrogate other difficult-to-measure kinetic processes, such as 1) pathobiological factors that are patient dependent, diverse in nature, and will for certain happen during the course of disease and treatments (e.g., disease progression leading to tumor size increase and/or micrometastasis, chemotherapy-induced apoptosis leading to changes in tumor cell density and interstitial void volume fraction, and antiangiogenicinduced changes in vasculatures and blood flow); 
and 2) environment- and time-dependent changes in ECM components or structures that would alter the NP transport and functionality. In short, QSP, although still in its infancy, represents a potentially useful tool to predict the NP delivery and residence at the therapeutic and toxicity targets or organs, and thereby improves in vitro to in vivo and preclinical to clinical translations and enables the prediction of the clinical safety profile and efficacy of NP products.

\section{Authorship Contributions}

Wrote or contributed to the writing of the manuscript: Au, Abbiati, Wientjes, Lu.

\section{References}

Abbiati RA and Au JL (2018) Quantitative systems pharmacology on cancer drug delivery to target sites: application of chemical engineering tools, in Quantitative Systems Pharmacology: Models and Model-Based Systems with Applications (Manca D ed) pp 239-270, Elsevier, Amsterdam.

Abbiati RA, Yeung BZ, Jaiprasart P, Lu Z, Wientjes MG, and Au JL (2017a) Quantitative pharmacology to interrogate mechanisms of lipoplex destabilization by serum proteins (Abstract). FASEB J 31 (Suppl):829.1.

Abbiati RA, Yeung BZ, Lu Z, Wientjes MG, and Au JL (2017b) Quantitative pharmacology of internalization, intracellular trafficking and gene silencing of siRNA (Abstract). FASEB J 31 (Suppl):828.6

Ahsan SM, Rao CM, and Ahmad MF (2018) Nanoparticle-protein interaction: the significance and role of protein corona. Adv Exp Med Biol 1048:175-198.

Andar AU, Hood RR, Vreeland WN, Devoe DL, and Swaan PW (2014) Microfluidic preparation of liposomes to determine particle size influence on cellular uptake mechanisms. Pharm Res 31:401-413.

Au JL, Guo P, Gao Y, Lu Z, Wientjes MG, Tsai M, and Wientjes MG (2014) Multiscale tumor spatiokinetic model for intraperitoneal therapy. AAPS J 16:424-439.

$\mathrm{Au}$ JL, Jang SH, and Wientjes MG (2002) Clinical aspects of drug delivery to tumors. $J$ Control Release 78:81-95.

Au JL, Jang SH, Zheng J, Chen CT, Song S, Hu L, and Wientjes MG (2001) Determinants of drug delivery and transport to solid tumors. J Control Release 74:31-46. $\mathrm{Au}$ JL, Lu Z, and Wientjes MG (2015) Versatility of particulate carriers: development of pharmacodynamically optimized drug-loaded microparticles for treatment of peritoneal cancer. AAPS J 17:1065-1079.

Au JL, Yeung BZ, Wientjes MG, Lu Z, and Wientjes MG (2016) Delivery of cancer therapeutics to extracellular and intracellular targets: determinants, barriers, challenges and opportunities. Adv Drug Deliv Rev 97:280-301.

Barbero F, Russo L, Vitali M, Piella J, Salvo I, Borrajo ML, Busquets-Fité M, Grandori R, Bastús NG, Casals E, et al. (2017) Formation of the protein corona: the interface between nanoparticles and the immune system. Semin Immunol 34:52-60.

Bargheer D, Nielsen J, Gébel G, Heine M, Salmen SC, Stauber R, Weller H, Heeren J, and Nielsen $\mathrm{P}(2015)$ The fate of a designed protein corona on nanoparticles in vitro and in vivo. Beilstein $J$ Nanotechnol 6:36-46.

Behzadi S, Serpooshan V, Sakhtianchi R, Müller B, Landfester K, Crespy D, and Mahmoudi M (2014) Protein corona change the drug release profile of nanocarriers: the "overlooked" factor at the nanobio interface. Colloids Surf B Biointerfaces 123:143-149.

Behzadi S, Serpooshan V, Tao W, Hamaly MA, Alkawareek MY, Dreaden EC, Brown D, Alkilany AM, Farokhzad OC, and Mahmoudi M (2017) Cellular uptake of nanoparticles: journey inside the cell. Chem Soc Rev 46:4218-4244.

Bobo D, Robinson KJ, Islam J, Thurecht KJ, and Corrie SR (2016) Nanoparticlebased medicines: a review of FDA-approved materials and clinical trials to date. Pharm Res 33:2373-2387.

Bonvin D, Aschauer U, Alexander DTL, Chiappe D, Moniatte M, Hofmann H, and Mionić Ebersold M (2017) Protein corona: impact of lymph versus blood in a complex in vitro environment. Small 13:1700409.

Buyens K, Lucas B, Raemdonck K, Braeckmans K, Vercammen J, Hendrix J, Engelborghs Y, De Smedt SC, and Sanders NN (2008) A fast and sensitive method for measuring the integrity of siRNA-carrier complexes in full human serum. $J$ Control Release 126:67-76.

Caputo D, Papi M, Coppola R, Palchetti S, Digiacomo L, Caracciolo G, and Pozzi D (2017) A protein corona-enabled blood test for early cancer detection. Nanoscale 9:349-354.

Chen F, Wang G, Griffin JI, Brenneman B, Banda NK, Holers VM, Backos DS, Wu L Moghimi SM, and Simberg D (2017) Complement proteins bind to nanoparticle protein corona and undergo dynamic exchange in vivo. Nat Nanotechnol 12:387-393.

Clark JM, Whitney RR, Olsen SJ, George RJ, Swerdel MR, Kunselman L, and Bonner DP (1991) Amphotericin B lipid complex therapy of experimental fungal infections in mice. Antimicrob Agents Chemother 35:615-621.

Conrads TP, Fusaro VA, Ross S, Johann D, Rajapakse V, Hitt BA, Steinberg SM, Kohn EC, Fishman DA, Whitely G, et al. (2004) High-resolution serum proteomic features for ovarian cancer detection. Endocr Relat Cancer 11:163-178.

Corbo C, Molinaro R, Tabatabaei M, Farokhzad OC, and Mahmoudi M (2017) Personalized protein corona on nanoparticles and its clinical implications. Biomater Sci 5:378-387.
Costa-Silva B, Aiello NM, Ocean AJ, Singh S, Zhang H, Thakur BK, Becker A, Hoshino A, Mark MT, Molina H, et al. (2015) Pancreatic cancer exosomes initiate pre-metastatic niche formation in the liver. Nat Cell Biol 17:816-826.

Dobrovolskaia MA, Neun BW, Man S, Ye X, Hansen M, Patri AK, Crist RM, and McNeil SE (2014) Protein corona composition does not accurately predict hematocompatibility of colloidal gold nanoparticles. Nanomedicine (Lond) 10:1453-1463.

Doherty GJ and McMahon HT (2009) Mechanisms of endocytosis. Annu Rev Biochem 78:857-902.

Fang L, Kim MJ, Li Z, Wang Y, DiLiberti CE, Au J, Hooker A, Ducharme MP, Lionberger R, and Zhao L (2018) Model-informed drug development and review for generic products: summary of FDA public workshop. Clin Pharmacol Ther 104:27-30.

Fisher DT, Muhitch JB, Kim M, Doyen KC, Bogner PN, Evans SS, and Skitzki JJ (2016) Intraoperative intravital microscopy permits the study of human tumour vessels. Nat Commun 7:10684.

Flynn GL, Yalkowsky SH, and Roseman TJ (1974) Mass transport phenomena and models: theoretical concepts. J Pharm Sci 63:479-510.

Gabriel EM, Fisher DT, Evans S, Takabe K, and Skitzki JJ (2018) Intravital microscopy in the study of the tumor microenvironment: from bench to human application. Oncotarget 9:20165-20178.

Gao Y, Li M, Chen B, Shen Z, Guo P, Wientjes MG, and Au JL (2013) Predictive models of diffusive nanoparticle transport in 3-dimensional tumor cell spheroids. AAPS J 15:816-831.

Hadjidemetriou M, Al-Ahmady Z, and Kostarelos K (2016) Time-evolution of in vivo protein corona onto blood-circulating PEGylated liposomal doxorubicin (DOXIL) nanoparticles. Nanoscale 8:6948-6957.

Hadjidemetriou M, Al-Ahmady Z, Mazza M, Collins RF, Dawson K, and Kostarelos K (2015) In vivo biomolecule corona around blood-circulating, clinically used and antibody-targeted lipid bilayer nanoscale vesicles. ACS Nano 9:8142-8156.

Hanash S (2003) Disease proteomics. Nature 422:226-232.

Helenius A, Mellman I, Wall D, and Hubbard A (1983) Endosomes. Trends Biochem Sci 8:245-250.

Hendriks BS, Reynolds JG, Klinz SG, Geretti E, Lee H, Leonard SC, Gaddy DF, Espelin CW, Nielsen UB, and Wickham TJ (2012) Multiscale kinetic modeling of liposomal doxorubicin delivery quantifies the role of tumor and drug-specific parameters in local delivery to tumors. CPT Pharmacometrics Syst Pharmacol 1:e15.

Huang R, Carney RP, Stellacci F, and Lau BL (2013) Protein-nanoparticle interactions: the effects of surface compositional and structural heterogeneity are scale dependent. Nanoscale 5:6928-6935.

Huotari J and Helenius A (2011) Endosome maturation. EMBO J 30:3481-3500.

Jain RK, Tong RT, and Munn LL (2007) Effect of vascular normalization by antiangiogenic therapy on interstitial hypertension, peritumor edema, and lymphatic metastasis: insights from a mathematical model. Cancer Res 67:2729-2735.

Jang SH, Wientjes MG, Lu D, and Au JL (2003) Drug delivery and transport to solid tumors. Pharm Res 20:1337-1350.

Jayaram DT, Pustulka SM, Mannino RG, Lam WA, and Payne CK (2018) Protein corona in response to flow: effect on protein concentration and structure. Biophys $J$ 115:209-216.

Jiang Y, Tang R, Duncan B, Jiang Z, Yan B, Mout R, and Rotello VM (2015) Direct cytosolic delivery of siRNA using nanoparticle-stabilized nanocapsules. Angew Chem Int Ed Engl 54:506-510.

Johnson EM, Ojwang JO, Szekely A, Wallace TL, and Warnock DW (1998) Comparison of in vitro antifungal activities of free and liposome-encapsulated nystatin with those of four amphotericin B formulations. Antimicrob Agents Chemother 42:1412-1416.

Ke PC, Lin S, Parak WJ, Davis TP, and Caruso F (2017) A decade of the protein corona. ACS Nano 11:11773-11776.

Keener J and Sneyd J (2009) Mathematical Physiology, Springer-Verlag, New York. Khalil IA, Kogure K, Akita H, and Harashima H (2006) Uptake pathways and subsequent intracellular trafficking in nonviral gene delivery. Pharmacol Rev 58:32-45.

Kinnear C, Moore TL, Rodriguez-Lorenzo L, Rothen-Rutishauser B, and Petri-Fink A (2017) Form follows function: nanoparticle shape and its implications for nanomedicine. Chem Rev 117:11476-11521.

Lai ZW, Yan Y, Caruso F, and Nice EC (2012) Emerging techniques in proteomics for probing nano-bio interactions. ACS Nano 6:10438-10448.

Li Y, Wang J, Wientjes MG, and Au JL (2012) Delivery of nanomedicines to extracellular and intracellular compartments of a solid tumor. Adv Drug Deliv Rev 64:29-39.

Lu JJ, Langer R, and Chen J (2009) A novel mechanism is involved in cationic lipidmediated functional siRNA delivery. Mol Pharm 6:763-771.

$\mathrm{Lu} \mathrm{Z}$, Wang J, Wientjes MG, and Au JL (2010) Intraperitoneal therapy for peritoneal cancer. Future Oncol 6:1625-1641.

Lu Z, Wientjes MG, and Au JL (2015) Development of drug-loaded particles for intraperitoneal therapy, in Intraperitoneal Cancer Therapy: Principles and Practice (Ceelen WP and Levine EA eds) pp 331-344, CRC Press, Boca Raton, FL.

Macheras P and Iliadis A (2006) Modeling in Biopharmaceutics, Pharmacokinetics and Pharmacodynamics: Homogeneous and Heterogeneous Approaches, Springer International Publishing, New York.

Mahmoudi M (2018) Debugging nano-bio interfaces: systematic strategies to accelerate clinical translation of nanotechnologies. Trends Biotechnol 36:755-769.

Mastorakos P, Zhang C, Berry S, Oh Y, Lee S, Eberhart CG, Woodworth GF, Suk JS, and Hanes J (2015) Highly PEGylated DNA nanoparticles provide uniform and widespread gene transfer in the brain. Adv Healthc Mater 4:1023-1033.

Mathivanan S, Ji H, and Simpson RJ (2010) Exosomes: extracellular organelles important in intercellular communication. J Proteomics 73:1907-1920.

McMahon HT and Boucrot E (2011) Molecular mechanism and physiological functions of clathrin-mediated endocytosis. Nat Rev Mol Cell Biol 12:517-533.

Melo SA, Sugimoto H, O’Connell JT, Kato N, Villanueva A, Vidal A, Qiu L, Vitkin E, Perelman LT, Melo CA, et al. (2014) Cancer exosomes perform cell-independent microRNA biogenesis and promote tumorigenesis. Cancer Cell 26:707-721. 
Mercer J and Helenius A (2009) Virus entry by macropinocytosis. Nat Cell Biol 11:510-520.

Monopoli MP, Aberg C, Salvati A, and Dawson KA (2012) Biomolecular coronas provide the biological identity of nanosized materials. Nat Nanotechnol 7:779-786.

Monteiro-Riviere NA, Samberg ME, Oldenburg SJ, and Riviere JE (2013) Protein binding modulates the cellular uptake of silver nanoparticles into human cells: implications for in vitro to in vivo extrapolations? Toxicol Lett 220:286-293.

Müller J and Kuttler C (2015) Methods and Models in Mathematical Biology: Deterministic and Stochastic, Springer-Verlag, Berlin.

Muller L, Mitsuhashi M, Simms P, Gooding WE, and Whiteside TL (2016) Tumorderived exosomes regulate expression of immune function-related genes in human T cell subsets. Sci Rep 6:20254

Müller LK, Simon J, Rosenauer C, Mailänder V, Morsbach S, and Landfester K (2018) The transferability from animal models to humans: challenges regarding aggregation and protein corona formation of nanoparticles. Biomacromolecules 19:374-385.

Naslavsky N and Caplan S (2018) The enigmatic endosome - sorting the ins and outs of endocytic trafficking. J Cell Sci 131:jcs216499.

Nie S (2010) Understanding and overcoming major barriers in cancer nanomedicine. Nanomedicine (Lond) 5:523-528.

Nuytten N, Hakimhashemi M, Ysenbaert T, Defour L, Trekker J, Soenen SJ, Van der Meeren P, and De Cuyper M (2010) PEGylated lipids impede the lateral diffusion of adsorbed proteins at the surface of (magneto)liposomes. Colloids Surf B Biointerfaces 80:227-231.

Oh N and Park JH (2014) Endocytosis and exocytosis of nanoparticles in mammalian cells. Int J Nanomedicine 9 (Suppl 1):51-63.

Paliwal SR, Paliwal R, and Vyas SP (2015) A review of mechanistic insight and application of $\mathrm{pH}$-sensitive liposomes in drug delivery. Drug Deliv 22:231-242.

Pelaz B, del Pino P, Maffre P, Hartmann R, Gallego M, Rivera-Fernández S, de la Fuente JM, Nienhaus GU, and Parak WJ (2015) Surface functionalization of nanoparticles with polyethylene glycol: effects on protein adsorption and cellular uptake. ACS Nano 9:6996-7008.

Prabhakar U, Maeda H, Jain RK, Sevick-Muraca EM, Zamboni W, Farokhzad OC Barry ST, Gabizon A, Grodzinski P, and Blakey DC (2013) Challenges and key considerations of the enhanced permeability and retention effect for nanomedicine drug delivery in oncology. Cancer Res 73:2412-2417.

Qu L, Ding J, Chen C, Wu ZJ, Liu B, Gao Y, Chen W, Liu F, Sun W, Li XF, et al. (2016) Exosome-transmitted lncARSR promotes sunitinib resistance in renal cancer by acting as a competing endogenous RNA. Cancer Cell 29:653-668.

Rahman M, Laurent S, Tawil N, Yahia L, and Mahmoudi M (2013) Nanoparticle and protein corona, in Protein-Nanoparticle Interactions: The Bio-Nano Interface. pp 21-44, Springer, Berlin.

Raoufi M, Hajipour MJ, Kamali Shahri SM, Schoen I, Linn U, and Mahmoudi M (2018) Probing fibronectin conformation on a protein corona layer around nanoparticles. Nanoscale 10:1228-1233.

Raposo G and Stoorvogel W (2013) Extracellular vesicles: exosomes, microvesicles, and friends. J Cell Biol 200:373-383.

Rejman J, Oberle V, Zuhorn IS, and Hoekstra D (2004) Size-dependent internalization of particles via the pathways of clathrin- and caveolae-mediated endocytosis. Biochem J 377:159-169.

Ritz S, Schöttler S, Kotman N, Baier G, Musyanovych A, Kuharev J, Landfester K, Schild H, Jahn O, Tenzer S, et al. (2015) Protein corona of nanoparticles: distinct proteins regulate the cellular uptake. Biomacromolecules 16:1311-1321.

Riviere JE (2013) Of mice, men and nanoparticle biocoronas: are in vitro to in vivo correlations and interspecies extrapolations realistic? Nanomedicine (Lond) 8:1357-1359.

Robbins PD and Morelli AE (2014) Regulation of immune responses by extracellular vesicles. Nat Rev Immunol 14:195-208.

Sarin H (2010) Physiologic upper limits of pore size of different blood capillary types and another perspective on the dual pore theory of microvascular permeability. $J$ Angiogenes Res 2:14.

Schroeder A, Levins CG, Cortez C, Langer R, and Anderson DG (2010) Lipid-based nanotherapeutics for siRNA delivery. J Intern Med 267:9-21.

Sefidgar M, Soltani M, Raahemifar K, Bazmara H, Nayinian SM, and Bazargan M (2014) Effect of tumor shape, size, and tissue transport properties on drug delivery to solid tumors. J Biol Eng 8:12.
Selva Sharma A and Ilanchelian M (2015) Comprehensive multispectroscopic analysis on the interaction and corona formation of human serum albumin with gold/ silver alloy nanoparticles. J Phys Chem B 119:9461-9476.

Setyawati MI, Tay CY, Docter D, Stauber RH, and Leong DT (2015) Understanding and exploiting nanoparticles' intimacy with the blood vessel and blood. Chem Soc Rev 44:8174-8199.

Shang L, Nienhaus K, and Nienhaus GU (2014) Engineered nanoparticles interacting with cells: size matters. J Nanobiotechnology 12:5.

Sharma KR (2010) Transport Phenomena in Biomedical Engineering: Artifical Organ Design and Development, and Tissue Engineering, McGraw-Hill Companies, Inc, New York.

Soltani M and Chen P (2011) Numerical modeling of fluid flow in solid tumors. PLoS One 6:e20344.

Stone L (2016) Kidney cancer: exosome transmission of sunitinib resistance. Nat Rev Urol 13:297.

Strojan K, Leonardi A, Bregar VB, Križaj I, Svete J, and Pavlin M (2017) Dispersion of nanoparticles in different media importantly determines the composition of their protein corona. PLoS One 12:e169552.

Tenzer S, Docter D, Kuharev J, Musyanovych A, Fetz V, Hecht R, Schlenk F, Fischer D, Kiouptsi K, Reinhardt C, et al. (2013) Rapid formation of plasma protein corona critically affects nanoparticle pathophysiology. Nat Nanotechnol 8:772-781.

Treuel L, Docter D, Maskos M, and Stauber RH (2015) Protein corona - from molecular adsorption to physiological complexity. Beilstein J Nanotechnol 6:857-873.

Treuel L and Nienhaus GU (2012) Toward a molecular understanding of nanoparticle-protein interactions. Biophys Rev 4:137-147.

U.S. Food and Drug Administration (2018) Pilot meetings program for modelinformed drug development approaches. Fed Regist 83:16868-16870

Usmani SS, Bedi G, Samuel JS, Singh S, Kalra S, Kumar P, Ahuja AA, Sharma M, Gautam A, and Raghava GPS (2017) THPdb: database of FDA-approved peptide and protein therapeutics. PLoS One 12:e0181748.

van Niel G, D'Angelo G, and Raposo G (2018) Shedding light on the cell biology of extracellular vesicles. Nat Rev Mol Cell Biol 19·213-228.

Vilanova O, Mittag JJ, Kelly PM, Milani S, Dawson KA, Rädler JO, and Franzese G (2016) Understanding the kinetics of protein-nanoparticle corona formation. ACS Nano 10:10842-10850.

Walkey CD and Chan WC (2012) Understanding and controlling the interaction of nanomaterials with proteins in a physiological environment. Chem Soc Rev 41: $2780-2799$

Walkey CD, Olsen JB, Guo H, Emili A, and Chan WC (2012) Nanoparticle size and surface chemistry determine serum protein adsorption and macrophage uptake. $J$ Am Chem Soc 134:2139-2147.

Wang J, Lu Z, Gao Y, Wientjes MG, and Au JL (2011) Improving delivery and efficacy of nanomedicines in solid tumors: role of tumor priming. Nanomedicine (Lond) 6:1605-1620.

Wang J, Lu Z, Wientjes MG, and Au JL (2010) Delivery of siRNA therapeutics: barriers and carriers. AAPS J 12:492-503.

Wang J, Yeung BZ, Cui M, Peer CJ, Lu Z, Figg WD, Guillaume Wientjes M, Woo S, and Au JL (2017) Exosome is a mechanism of intercellular drug transfer: application of quantitative pharmacology. J Control Release 268:147-158.

Wientjes MG, Yeung BZ, Lu Z, Wientjes MG, and Au JL (2014) Predicting diffusive transport of cationic liposomes in 3-dimensional tumor spheroids. J Control Release 192:10-18.

Winzen S, Schoettler S, Baier G, Rosenauer C, Mailaender V, Landfester K, and Mohr K (2015) Complementary analysis of the hard and soft protein corona: sample preparation critically effects corona composition. Nanoscale 7:2992-3001.

Yang H, Chen Z, Zhang L, Yung WY, Leung KC, Chan HY, and Choi CH (2016) Mechanism for the cellular uptake of targeted gold nanorods of defined aspect ratios. Small 12:5178-5189.

Yang ST, Liu Y, Wang YW, and Cao A (2013) Biosafety and bioapplication of nanomaterials by designing protein-nanoparticle interactions. Small 9:1635-1653.

Zhang X, Zhang J, Zhang F, and Yu S (2017) Probing the binding affinity of plasma proteins adsorbed on Au nanoparticles. Nanoscale 9:4787-4792.

Zheng N, Sun DD, Zou P, and Jiang W (2017) Scientific and regulatory considerations for generic complex drug products containing nanomaterials. AAPS $J$ 19:619-631. 